
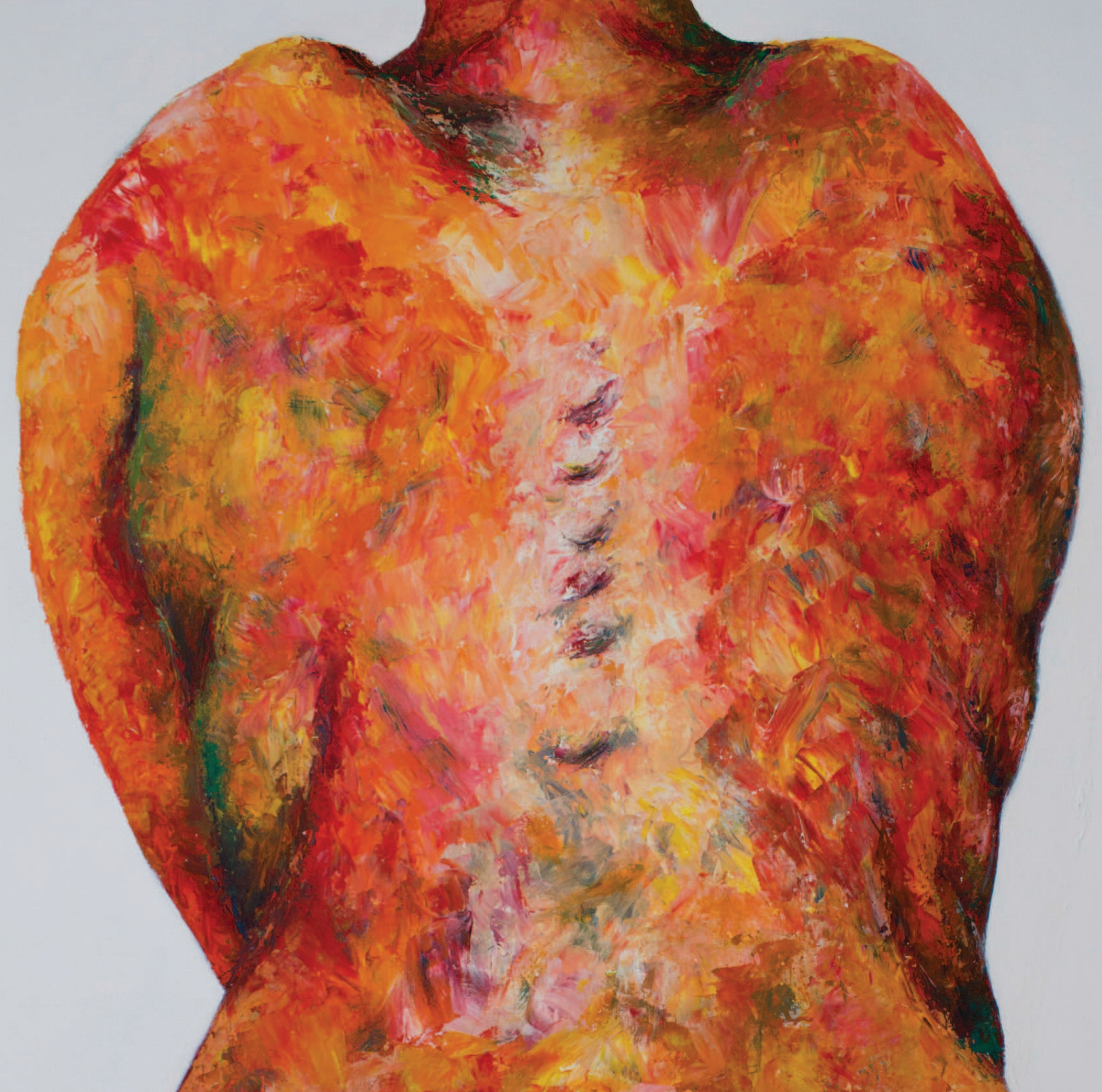

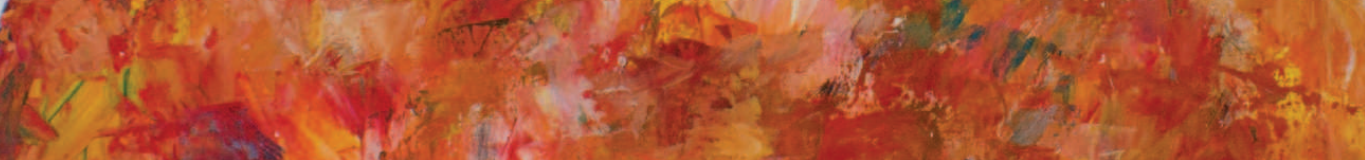

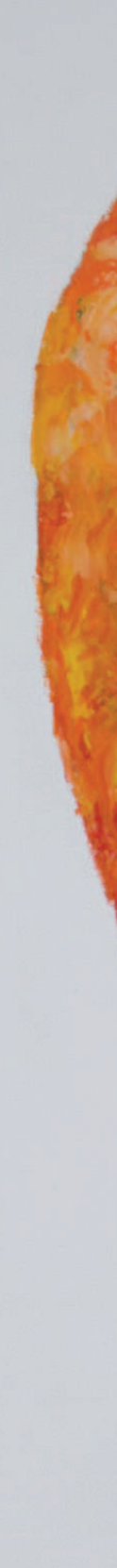

1

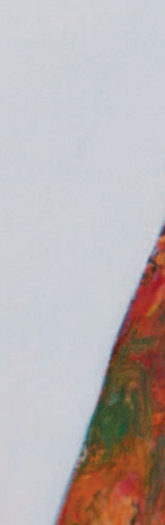

2.

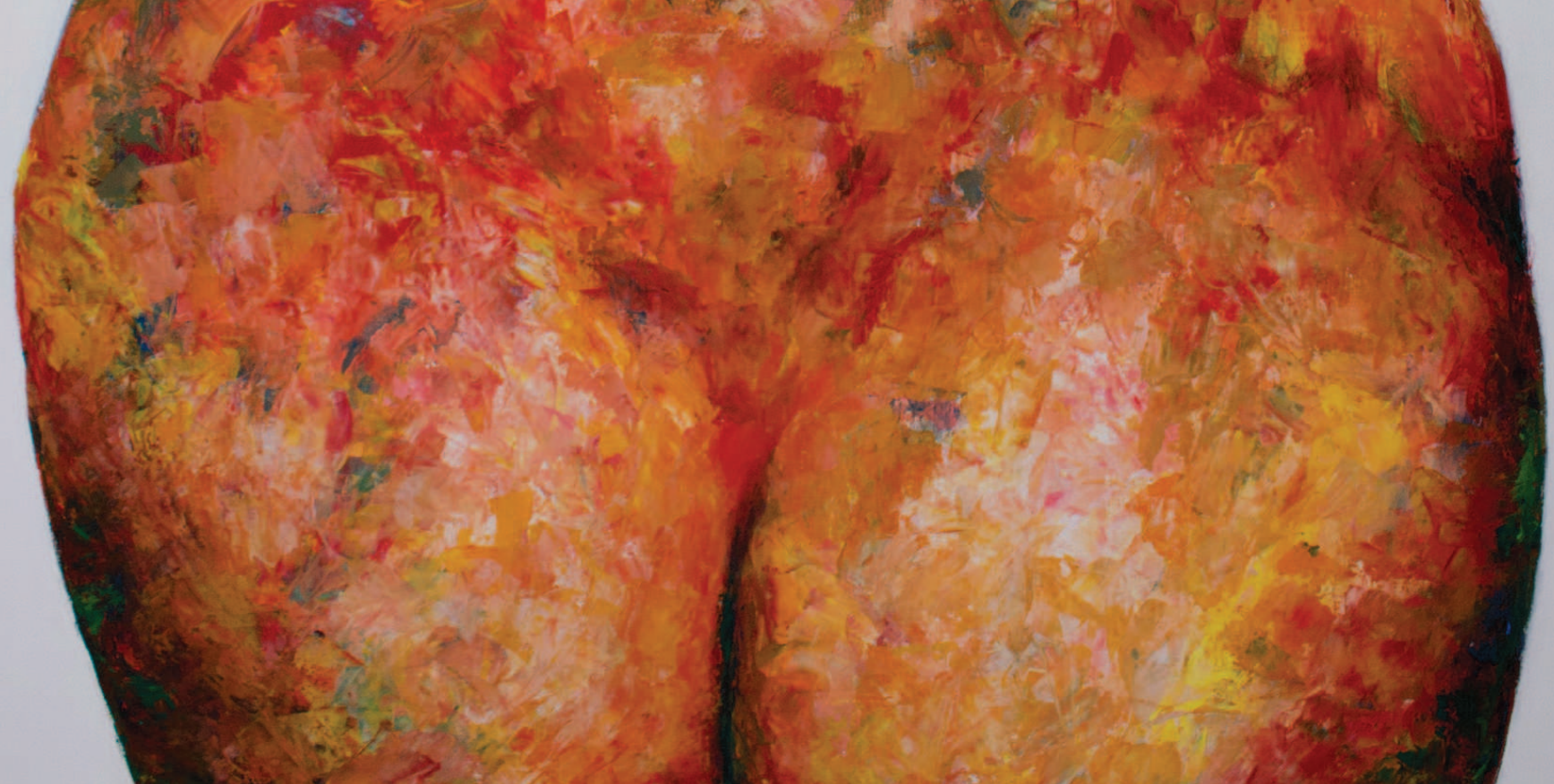




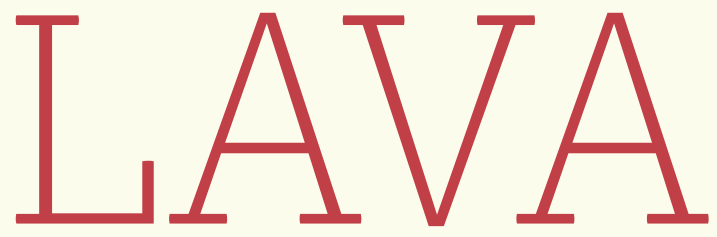

Matéria liquida lançada pelos vulcões.

Torrente, enxurrada, curso. 


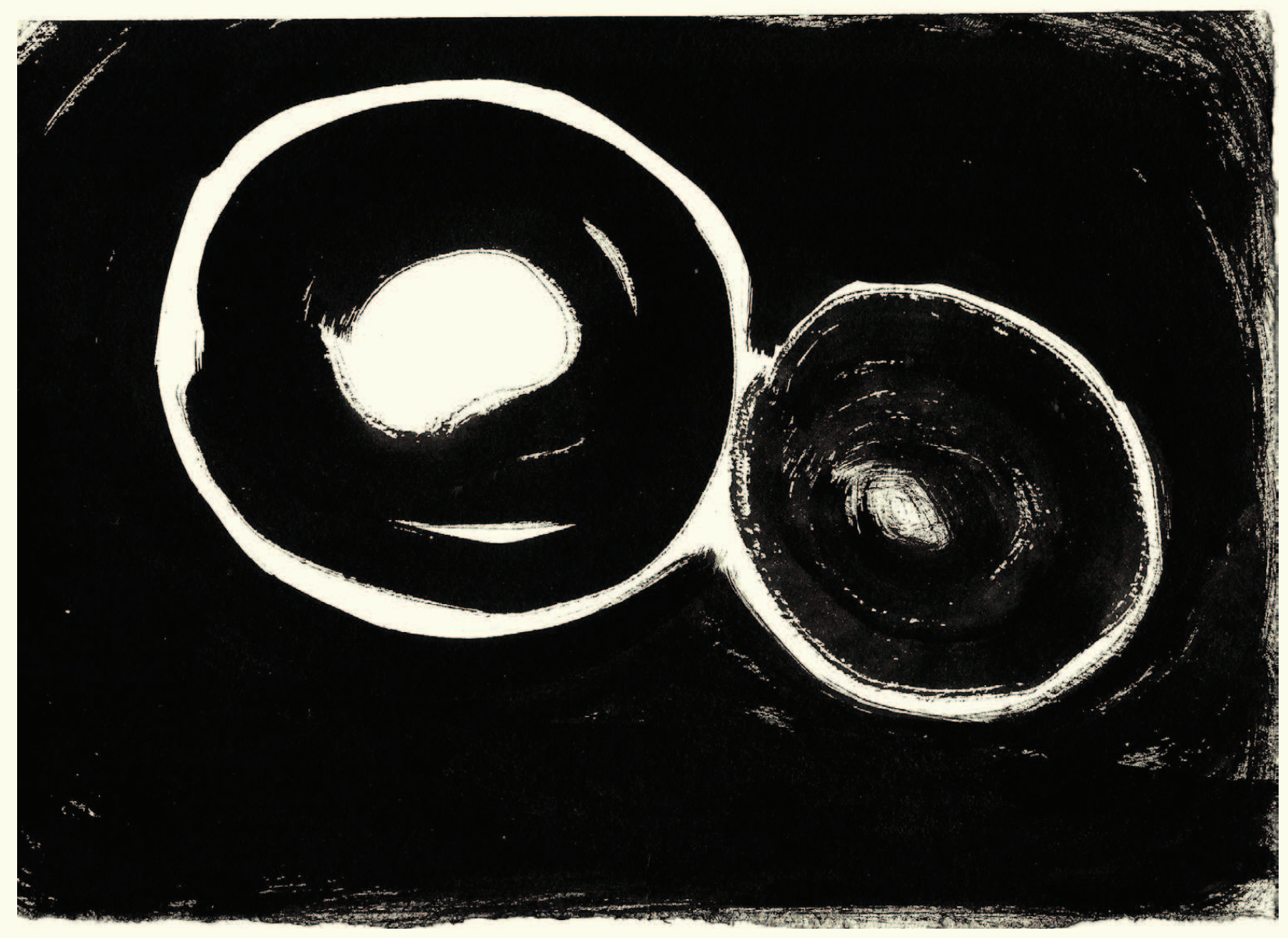

\section{PROSA, DRAMA E PERFORMANCE NA OBRA FINAL DE SAMUEL BECKETT}

Textos de conclusão do curso ministrado no segundo semestre de 2014 e indicados para publicação pelo Profo Fábio de Souza Andrade. 


\title{
SAMUEL BECKETT: DE DRAMATURGO A ENCENADOR
}

\author{
- FELIPE AUGUSTO DE SOUZA SANTOS
}

\section{RESUMO}

Este artigo tem como objetivo abordar o percurso de Samuel Beckett como encenador de suas próprias peças de teatro, a partir de uma análise de aspectos do processo de encenação da peça A última gravação de Krapp [Krapp's last tape], dirigida por Beckett em 1969 no Schiller-Theater Werkstatt de Berlim. A reflexão terá como ponto de partida a relação de Beckett com a encenação teatral, desde seu primeiro contato acompanhando processos de criação de encenadores renomados como Roger Blin, e a transição de observador e conselheiro de projetos de outros diretores a encenador, tendo como premissa um cuidadoso rigor estético sobre o material dramatúrgico e sobre a transposição desse material para o palco, a partir das particularidades relativas ao trabalho de interpretação dos atores e à própria encenação teatral, ou seja, a tensão entre texto e cena.

Palavras-chave: Samuel Beckett, Beckett diretor, dramaturgia, encenação, texto e cena

\section{ABSTRACT}

This article aims to investigate the course of Samuel Beckett as director of his own theatre plays, from an analysis of aspects of the staging process of Krapp's last tape, directed by Beckett in 1969 at the Schiller-Theater Werkstatt in Berlin. The reflection will have as a starting point Beckett's relationship with the theatrical staging, from his first contact accompanying processes of creation of renowned directors such as Roger Blin, and the transition of observer and adviser of projects of other directors to director, taking as its premise a careful aesthetic rigour on the dramaturgic material and on the transposition of this material to the stage, from the particularities relating to the work of interpretation of the actors and the theatrical staging, namely the tension between text and scene.

Keywords: Samuel Beckett, Beckett as director, dramaturgy, staging, text and scene

\section{A TRAJETÓRIA DE DRAMATURGO A ENCENADOR}

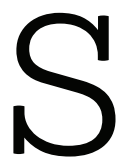
amuel Beckett foi um dos mais importantes dramaturgos do século XX, cuja influência em relação ao teatro contemporâneo pode ser percebida não apenas no campo da dramaturgia, mas também nos campos da estética teatral, da iluminação teatral e sobretudo 
da encenação teatral. Este artigo tem como tema central a trajetória de Beckett como encenador, e para tanto faremos uma opção pela reflexão sobre as peças que refletem a estética desenvolvida em seu teatro a partir de Esperando Godot, deixando de lado, portanto, suas primeiras experiências ligadas ao palco, relacionadas a suas primeiras obras dramatúrgicas, Le kid, paródia dramática do Cid, de Corneille, Human wishes, fragmento abandonado e não concluído pelo autor, e Eleutheria, obra que precedeu Esperando Godot e que foi publicada apenas após a morte do autor, mantendo o foco em seu trabalho como encenador de suas próprias peças, iniciado em 1967 com a encenação de Fim de partida, no Schiller-Theater de Berlim, e encerrada com a encenação de Dias felizes, apresentada no Royal Court Theatre de Londres em 1979.

$\mathrm{O}$ caminho de Beckett rumo à encenação teatral se inicia realmente quando é chamado por Roger Blin para acompanhar os ensaios de sua montagem de Esperando Godot, cuja estreia ocorre em Paris no dia 19 de janeiro de 1953, no Théâtre de Babylone. É neste momento, coincidentemente, que Beckett inicia o trabalho de tradução de suas próprias peças. O contato com Blin, um dos mais renomados encenadores franceses do período, descortina a Beckett o universo da encenação profissional parisiense. A partir desse momento, Beckett iniciará uma série de parcerias com Blin e outros encenadores, como o americano Alan Schneider, trabalhando como consultor acerca de suas peças, como uma forma de assegurar certo parâmetro em relação à forma e à estética de sua dramaturgia.

Durante os ensaios de Godot, Beckett ainda não tinha a grande experiência com teatro que adquiriu posteriormente, mas já dispunha de um conhecimento muito preciso do teatro como espetáculo, ou seja, como um acontecimento que se desenrola sobre um palco. [Aliás, note-se que, ao contrário de tantos outros autores, ele sempre se recusou a escrever sobre teatro ou especificamente sobre suas obras.] No texto, ele indicava os movimentos, os tempos que desejava, mas essas indicações dirigiam-se sobretudo ao leitor: uma vez no palco, as coisas mudam. É preciso levar em conta o imponderável da personalidade do ator, as imposições materiais, o valor expressivo de certas palavras. Ali, Beckett rapidamente se deu conta daquilo que apenas antecipara abstratamente, e submeteu-se de bom grado a minhas indicações: buscando uma estilização a priori, aprovava os ajustes na execução. Não se mostrava inimigo dos achados, mas fazia absoluta questão que fossem orgânica e totalmente justificados. (Buin apud BECKETT, 2005, p. 203) 
Portanto, a falta de experiência prática em teatro profissional foi sendo gradativamente substituída por um aprendizado junto aos encenadores com quem Beckett trabalhava como consultor e em especial com Roger Blin, com quem trabalharia em parceria em diversas montagens, entre elas Fim de partida e Dias felizes. Segundo Luiz Fernando Ramos:

[...] entre a estreia de Esperando Godot, em 1953, e a primeira montagem em que assina a direção - Fim de jogo, no Schiller-Theater de Berlim, em 1967 - passaram-se catorze anos de aprendizado da carpintaria teatral. Foi um tempo em que as convicções do escritor sobre o teatro foram temperadas pelas muitas horas de vivência de palco, experimentadas ao longo de diversas montagens de textos seus, uma boa parte das quais sob a direção de Roger Blin. O diretor francês foi, desde a primeira hora, um colaborador solidário, que, sem impor-se como autoridade cênica sobre o texto de Beckett, não se limitou a seguir cegamente as indicações do dramaturgo, introduzindo elementos novos sempre que se mostraram necessários. Essa verdadeira parceria Beckett-Blin, além de ter sido responsável por algumas das mais antológicas montagens da dramaturgia beckettiana, serviu ao próprio Beckett como aprendizado. (RAmos, 1999, p.77)

A partir desse primeiro contato com a encenação profissional de suas peças, o acompanhamento de montagens de outros diretores por Beckett aumentou gradativamente, bem como seu interesse em relação aos problemas específicos ligados à carpintaria teatral, especialmente no que se refere ao uso do espaço cênico e à iluminação. De acordo com Ruby Cohn:

Entre o final da década de 1950 e início da década de 1960 seu aconselhamento foi muitas vezes procurado para a encenação de suas peças, e seus conceitos em relação à performance dominaram várias produções dirigidas por outros encenadores, notadamente Fim de partida e Krapp em Londres em 1958, um Godot de 1961 e uma Comédie de 1964 em Paris, um Fim de partida em Paris-Londres em 1964, e o Godot do Royal Court em 1964. As encenações independentes de Beckett de suas próprias peças se iniciam em 1965, embora a primeira obra a ter o seu nome como diretor foi a peça televisiva Eh Joe em Stuttgart, no ano de 1966. (COHN, 1980, p.231, tradução nossa).

Foi este treinamento prático, equivalente a uma verdadeira formação como encenador, realizado pela via tradicional do aprendizado como assistente de direção [no caso de Beckett mais como observador 
e conselheiro do que como assistente], onde o contato com o dia a dia dos ensaios, a resolução dos problemas de ordem prática, a busca por soluções esteticamente inventivas, o diálogo constante com os atores dentro do fazer teatral, a preocupação com o texto que é falado em cena modificaram e aprimoraram a visão de Beckett em relação ao teatro e à própria cena. Não é de se estranhar quando Beckett menciona que para ele, durante o processo de encenação de Esperando Godot em 1953, o texto da peça parecia excessivamente verborrágico, como se não tivesse sido criado para o palco (GoNTARSKI, 2008).

Esse acompanhamento das encenações por parte de Beckett e o progressivo aprendizado mencionados permitiram que ele se aventurasse no terreno da direção teatral, se responsabilizando como encenador por montagens de Fim de partida em 1967, de A última gravação de Krapp em 1969, de Dias felizes em 1971, de Esperando Godot em 1975, de Footfalls e That time em 1976, e de Play em 1978 no Schiller-Theater berlinense, de Dias felizes no Royal Court Theatre de Londres, em 1979, bem como de trabalhos esporádicos em Paris e Londres.

Outro aspecto importante que parece ter conduzido Samuel Beckett em direção à encenação de suas peças foi a conhecida obsessão do autor pela versão final de suas obras. São conhecidas as inúmeras versões de determinados textos de sua autoria, especialmente no que se refere à dramaturgia, onde em alguns casos, devido às sucessivas revisões em busca do que Beckett chamava de "versão definitiva" de seus textos, chegavam a circular entre as casas editoriais que publicavam suas obras [Faber and Faber, Grove Press, John Calder e Éditions de Minuit] diferentes versões dos manuscritos beckettianos. Isso pode ser observado comparando-se algumas versões de suas peças, publicadas em diferentes edições, nas quais podemos notar pequenas modificações no texto, algumas das quais efetuadas após encenações realizadas pelo autor, como o aumento do número de passos em Footfalls de sete para nove ou a retirada do nariz purpúreo clownesco em $A$ última gravação de Krapp. Essa preocupação constante com a forma final de suas obras parece ter contribuído bastante para o interesse do autor em relação à prática da direção teatral.

Dentro desse aspecto, a busca de Beckett em se aprofundar cada vez mais no terreno da prática teatral parece, sem dúvida, estar mais ligada a uma busca pelo desenvolvimento e aprimoramento de uma estética teatral complexa e minimalista do que uma mera busca por controle de suas produções, ao contrário do que muitos que não conhecem a fundo sua obra pensam.

Recuperando o conceito de encenação, que surge na Europa na segunda metade do século XIX, mais especificamente dentro do que Patrice 
[1] AppiA, Adolphe. "Acteur, espace, lumière, peinture", in: Théâtre populaire, n. 5, enero-febrero, 1954, p. 38.

[2] Op. cit., p. 385.

[3] Em depoimento dado a Jonathan Kalb em 16 de novembro de 1986, Samuel Beckett deixava claro o motivo de sua oposição a métodos e práticas de encenadores contemporâneos: "Eu detesto esta escola moderna de direção. Para estes diretores o texto é apenas um pretexto para a sua própria ingenuidade". (BECKETT apud KALB, 1991, p. 71, tradução nossa)
Pavis chama de espacialização, "a encenação consiste em transpor a escritura dramática do texto em escritura cênica" (PAvis, 1983, p.385, tradução nossa). Segundo o teórico da encenação Adolphe Appia ${ }^{1}$, "a arte da encenação é a arte de projetar no espaço o que o dramaturgo pode projetar somente no tempo" (ApPIA apud PAVIS, 1983, p.385, tradução nossa). Portanto, para Pavis², "a encenação da obra de teatro consiste em encontrar para a partitura textual a concretização cênica mais apropriada ao espetáculo". Nesse sentido, parece que essa seria a verdadeira busca empreendida por Beckett ao iniciar seu trabalho como encenador de suas próprias peças, inclusive pelo fato de que ele se colocava como um "outro" ao encenar suas peças, como se seus textos tivessem sido escritos por um "outro", estabelecendo uma relação de alteridade dentro de sua própria obra.

Embora fosse um diretor extremamente metódico, realizando para cada uma de suas encenações longos estudos prévios das particularidades e estrutura dos textos, bem como a produção de cadernos de direção, preparados antes mesmo dos ensaios começarem, parece que Beckett não se interessava por métodos práticos de interpretação teatral ou de encenação ${ }^{3}$, como podemos observar quando afirma que "não é para mim esses Grotowskis e Métodos" (Beckett apud Mcmillan; Fehsenfeld, 1988, p. 16, tradução nossa). Por outro lado, em depoimento dado a Jean Reavey em Paris, em agosto de 1962, ele afirma que "você deve visualizar cada ação de seus personagens. Conhecer precisamente em que direção eles estão falando. Conhecer as pausas" (ВескетT apud MCMiLlan; FeHSEnFELD, 1988, p. 16, tradução nossa). Portanto não se trata de rejeitar qualquer método prático acerca da encenação teatral ou do trabalho prático dos atores, mas sim de rejeitar modelos pré-existentes em vigor no período em que trabalhava como diretor de suas peças em favor do desenvolvimento de seu próprio método de direção, que se por um lado muitas vezes parece algo rígido e ainda regido por princípios anteriores ao advento da encenação moderna [como a centralidade excessiva do texto e das leituras do diretor aos atores durante os ensaios], por outro lado demonstra um alto nível de consciência acerca das particularidades e do grau de complexidade de suas peças, bem como das necessidades práticas para que sejam transpostas para o palco. Mas se fizermos uma leitura atenta de alguns dos preceitos metodológicos stanislavskianos, para darmos um exemplo, percebemos que o ator e diretor russo trabalhava, como Beckett, com o que também chamava de visualização, e como Beckett, desenvolvia esse trabalho junto aos atores principalmente no início do processo de ensaios de um espetáculo, como Beckett procurava fazer antes do início de suas montagens, sendo que ambos, de diferentes maneiras, procuravam desenvolver o trabalho 
com a visualização de forma meticulosa, para somente em um segundo momento começarem a abordar as cenas no palco de forma prática.

Sobre a questão das leituras que Beckett fazia com os atores no início do processo de ensaios de suas peças, podemos pegar como exemplo o comentário de Billie Whitelaw acerca de sua relação como atriz em espetáculos dirigidos por Beckett:

\footnotetext{
Eu nunca trabalhei sem ele. Uma vez que eu o ouvi dizer ainda que duas ou três linhas de uma peça, então eu tenho uma ideia da área em que ele está trabalhando, o tempo dela. Então eu pego isso e vou mais e mais nessa direção, e, gradualmente, como um balão, isso começa a crescer. (WHITELAW apud KALB, 1991, p. 234, tradução nossa)
}

Mas essa visualização, ao que parece, não seria utilizada por Beckett apenas no momento dos ensaios práticos de uma montagem, mas sim desde o início do processo de escrita de uma obra, pois como menciona em um depoimento a Jean Reavey citado anteriormente, "eu nunca escrevo uma palavra sem antes dizê-la em alto e bom som" (BЕСKETT apud Mcmillan; FehSenfeld, 1988, p. 16, tradução nossa). Isso nos mostra claramente que a questão da visualização de suas criações começava desde o ato da escrita de um texto, e naturalmente, em relação à encenação, se estendia e aprofundava no processo de ensaios de suas peças. E mais do que isso, parece que a intenção de desdobrar seu olhar desde o processo de escrita de uma peça, atuando como um observador mental de sua própria obra amplie a perspectiva da visualização no sentido de propor diferentes perspectivas, possibilidades de produção de sentidos diversos por parte do leitor [e também do espectador]. Segundo Beckett, ainda em depoimento a Jean Reavey:

Quando eu escrevo uma peça, eu me coloco dentro dos personagens, eu também sou o autor suprindo as palavras, e eu me coloco na plateia visualizando o que acontece sobre o palco. (BескетT apud McMilLan; FeHSENFELd, 1988, p. 16, tradução nossa)

Em relação às suas montagens dirigidas no Schiller-Theater de Berlim, um dos atrativos para Beckett teria sido o distanciamento de suas peças gerado pelas traduções feitas por Elmar Tophoven, tradutor com quem Beckett trabalhou de forma próxima durante todas as suas encenações berlinenses. Isso parece reforçar a ideia de que Beckett, como encenador, buscava sempre tratar suas peças como objetos artísticos independentes, seja em relação a seu próprio trabalho de encenador, seja 
em relação ao trabalho de outros encenadores. A perspectiva da alteridade, sempre presente, permeia tanto sua dramaturgia como a própria forma de pensar e dirigir suas encenações, seja através da presença de um outro que atormenta a existência do sujeito, através de um olhar que observa impiedosamente esse sujeito ou até mesmo da necessidade da presença desse outro para poder existir.

Em relação ao trabalho das montagens de suas peças em Berlim, Beckett desenvolveu uma forma única e precisa de abordagem, burilada durante os longos anos de aprendizagem e observação de outros diretores, somada à experiência progressiva de seu próprio desenvolvimento como encenador. A pesquisadora Ruby Cohn faz uma síntese interessante acerca das etapas do processo de encenação das peças de Beckett por ele mesmo no Schiller-Theater:

Para as produções em Berlim, Beckett abordava suas peças basicamente da mesma maneira: 1) exame meticuloso das traduções para o alemão feitas por Tophoven e a subsequente correção a partir de sua própria versão em inglês [pelo fato de Tophoven traduzir a partir do francês]; 2) intensa visualização da peça no espaço teatral - o que Beckett chama de "tentando ver"; 3) compromisso do texto revisado alemão para a memória [incluindo direções de palco]; 4) composição de um caderno de direção ao qual ele não se referia durante os ensaios [...]; 5) transmissão de ideias sobre design a seu amigo Matias, que realiza uma primeira interpretação enquanto eles ainda estão em Paris. Apenas quando essas etapas estão completas que Beckett chega em Berlim Ocidental, onde as peças eram preparadas. (CoHN, 1980, p. 236, tradução nossa)

Falando sobre a encenação alemã de Esperando Godot, dirigida por Beckett no Schiller-Theater em 1975, Walter Asmus [seu assistente de direção e futuro diretor de montagens de peças de Beckett] menciona que:

Os ensaios são conduzidos de maneira convencional: após uma relativamente rápida leitura-geral do texto, o trabalho detalhado segue com intensidade crescente. $\mathrm{O}$ conteúdo não está sendo discutido, apenas [se necessário] as situações são esclarecidas, com algumas explicações sobre os personagens fornecidas. A grande precisão do trabalho e a luta para se manter a forma o mais amarrada possível são fascinantes por si só. (Asmus apud GoNTARSKI, 1986, p. 281, tradução nossa)

Ainda segundo Asmus, Beckett submetia seu próprio script constantemente a um controle crítico da maneira mais incrível e simpática. 
Também estava sempre aberto a sugestões durante os ensaios, e chegava até mesmo a pedir por elas (GonTARSKI, 1986, p. 281). Isso demonstra claramente um olhar de diretor sensível, extremamente consciente da necessidade de diálogo com os atores durante o processo de ensaios, permitindo através desse diálogo a sugestão criativa de seus parceiros atores e até mesmo remodelando a estrutura de seus textos a partir dos problemas práticos advindos da encenação.

Um exemplo interessante em relação a isso foi a modificação da iluminação de $A$ última gravação de Krapp a partir de um ensaio prático, onde o ator que interpretava o personagem Krapp, ao levantar-se, bateu com a cabeça na luminária que ficava posicionada próxima ao tampo da mesa do personagem. Ao realizar esse movimento [que poderia obviamente ser entendido como um erro], o ator proporcionou a Beckett uma visão interessante acerca da iluminação da cena, que passou a oscilar por alguns instantes imediatamente após o choque, provocando uma quebra interessante da iluminação estática e opressiva da peça. Outro exemplo, também advindo dos ensaios de A última gravação de Krapp, foi o acaso da iluminação do gravador de fitas de rolo iluminando a face do personagem após o blackout final da peça, proporcionando uma espécie de detalhe ambíguo, que prende a atenção do espectador e mantém a tensão da encenação mesmo após o término das ações físicas do personagem.

Um aspecto inventivo e inovador em relação à estética naturalista foi o uso diferenciado da quarta parede, tão cara a Stanislavski, em uma de suas direções. Em sua encenação de Footfalls em 1976, no Schiller-Theater, Beckett em um determinado momento paralisa a personagem May, como se estivesse em repouso, com sua cabeça apoiada na parede, mas essa "parede" seria a quarta parede do palco, isto é, justamente o espaço vazio e aberto da boca de cena, de onde o público observa o espetáculo.

\footnotetext{
Dessa maneira, a invisível quarta parede do teatro naturalista adquire uma nova e incomum dimensão. Como a sequência de tempo é incerta na primeira parte, consequentemente, na segunda parte, o espaço físico também se torna dúbio e misterioso. (KNowlson apud GonTARSKI, 1986, p. 355, tradução nossa)
}

Também é digna de nota a preocupação de Beckett, como encenador, em relação a aspectos que vão além da questão do texto dramatúrgico, aspectos práticos e técnicos que envolvem a encenação de uma peça, como som, luz e movimento. James Knowlson, ao abordar a encenação de Beckett da peça Footfalls em 1976, afirma que: 
Cada elemento em Footfalls é parte de uma coreografia total de som, luz e movimento. Como as notas de produção de Walter Asmus demonstram, Beckett era ansioso como diretor em fazer o nível da iluminação e do som uma parte do padrão formal como era o texto verbal. (KNOWLSON apud GoNTARSKI, 1986, p. 356, tradução nossa)

Para Gontarski (2008, p. 262), o Beckett que passa a dirigir suas peças a partir da encenação de Fim de partida em 1967 era um "outro", ou seja, não se tratava mais do Beckett que publicara Esperando Godot anos antes, mas sim um "outro" Beckett, um "outro" artista do teatro procurando olhar para suas peças escritas anos antes com um olhar nada canônico, no sentido de que não buscava apenas a mera execução e reprodução exata de suas obras dramatúrgicas na cena, mas que procurava dialogar com seus textos de forma a atualizá-los a partir de sua agora vasta experiência em sala de ensaio e no palco. Portanto, as encenações beckettianas buscavam um aprofundamento das questões centrais propostas inicialmente nos textos escritos, experimentando possibilidades para o melhor desenvolvimento e ambientação das cenas no palco e, ao mesmo tempo, mantendo abertas as possibilidades de entendimento e produção de sentidos por parte do público.

Se a forma como Beckett olhava para suas peças mudara, e podemos atestar isso na já citada passagem em que o autor, como encenador, critica a verborragia excessiva de Godot, o cuidado em deixar as situações em aberto, a ausência do menor comentário, inclusive em relação aos atores, acerca dos significados complexos de suas peças, isso se manteve absolutamente da mesma forma em relação à sua postura como autor dramático no início da década de 1950.

\section{O CADERNO DE DIREÇÃO DE A ÚLTIMA GRAVAÇÃO DE KRAPP}

Samuel Beckett encenou, a partir de 1967, as principais peças de sua dramaturgia e para cada montagem, produziu antecipadamente um caderno de direção, contendo de início todo seu complexo estudo acerca da encenação a ser realizada, bem como sugestões de modificação em relação aos textos escritos, como cortes e acréscimos, além de mapear detalhadamente os movimentos dos atores, configurando uma verdadeira partitura de ações físicas para cada personagem.

O registro dessas anotações, acessíveis até sua morte apenas a estudiosos, atores, diretores e demais colaboradores próximos a Beckett, foi publicado na forma da série The theatrical notebooks of Samuel 
Beckett, dividida em quatro volumes [Waiting for Godot, Endgame, Krapp's last tape e Shorter plays], além do volume acerca de Happy days, intitulado Happy days: Samuel Beckett's production notebook. Nestes volumes, publicados em parceria pelas editoras Faber and Faber e Grove Press, e tendo como editor geral o biógrafo e estudioso da obra beckettiana James Knowlson, são apresentados os cadernos de direção de Beckett de forma completa e integral, a partir de uma edição fac-simile dos originais, contendo também extensas anotações acerca das passagens marcadas por Beckett nos notebooks, bem como versões das peças contendo todos os cortes e alterações feitos por Beckett ao longo do processo de ensaios de cada montagem. Esses documentos constituem um verdadeiro achado para aqueles que se interessam pela obra teatral beckettiana, especialmente no que se refere à reflexão da cena como um todo, abarcando, além da dramaturgia, os elementos que concernem tanto à prática da interpretação, e consequentemente à visão que Beckett tinha acerca do trabalho do ator em sua dramaturgia, quanto à prática da direção teatral, e como a encenação de suas próprias peças era entendida por Beckett.

Conforme afirma Stanley Gontarski:

Esta associação autor-diretor ocorreu cerca de dezesseis vezes no palco e outras seis vezes no estúdio de televisão, durante vinte anos [1967-1986], com Beckett dirigindo suas peças em três idiomas, o inglês, o francês e o alemão. Durante cada um destes encontros Beckett apoderou-se da direção de seus textos para serem ambos, o "eu" e o "outro", ou seja, refinando, senão re-definindo, sua visão criativa para continuar a descobrir as possibilidades latentes de seu texto e reafirmar as fundações da estética modernista em seu trabalho. Expurgava então qualquer elemento que estimava estranho, assim demonstrando novamente seu envolvimento, senão sua preocupação com a forma, com o perfil estético de seu trabalho. (GoNTARSKI, 2008, p.262)

Acerca do complexo e extenso sistema de anotações que Beckett elaborava para cada montagem que dirigia, novamente citamos comentário de Stanley Gontarski:

Somente os cadernos de direção de Jogo [Play], escrita em 1962-3 e encenada por Beckett em 1978, contém em torno de 25 complexos e completos esboços, separados, organizados visual e oralmente, colocados lado a lado, paralelos ao respectivo texto escrito. Reverberações e ecos na preparação de sua própria encenação. (GoNTARSKI, 2008, p. 262) 
[4] Espécie de dupla representação em uma mesma noite, com duas sessões de espetáculos distintos sendo apresentados sequencialmente, ligados por temática ou autor, comum no teatro norte-americano.
Portanto, para Gontarski, "Beckett, resumindo, se transforma num grande teórico do espetáculo no processo de encenar e reescrever seu próprio texto dramático" (GoNTARSKI, 2008, p. 262).

Segundo James Knowlson, na introdução do The theatrical notebooks of Samuel Beckett Vol. III (KNowlson, 1992) acerca da montagem de $A$ última gravação de Krapp no Schiller-Theater Werkstatt, Beckett escreveu a peça nos dois primeiros meses de 1958, tendo desde o início o ator Patrick Magee em mente para o papel. Segundo o autor, a qualidade da voz "rachada" e envelhecida [ou gasta] do ator, além do acento e entonação irlandeses, foram os grandes atrativos para a criação do personagem, cujas características físicas talvez façam um paralelo a essa qualidade vocal do ator que gerara um grande interesse em Beckett, a ponto de a peça ter sido intitulada, por algum tempo, Magee monologue.

A primeira encenação, dirigida por Donald McWhinnie e interpretada por Patrick Magee, estreou no Royal Court Theatre de Londres, em outubro de 1958, e assim como a encenação parisiense estreada dezoito meses depois, e dirigida por Roger Blin, contou com a presença de Beckett como conselheiro durante os ensaios. No início de 1960, Beckett também se correspondera com o diretor americano Alan Schneider, por motivo da estreia da peça no Off-Broadway de Nova York, em um double-bill ${ }^{4}$ com Zoo story, de Edward Albee.

A encenação de $A$ última gravação de Krapp no Schiller-Theater Werkstatt não seria a única a contar com Beckett na direção ou no aconselhamento de outros diretores. Nos anos subsequentes, Beckett dirigiria o ator Jean Martin no papel de Krapp, no Théâtre Récamier em 1970, bem como acompanharia à distância uma encenação da peça para a BBC londrina, dirigida por Donald McWhinnie em 1972, além de auxiliar a montagem dirigida por Anthony Page, com Albert Finney no papel-título, preparando um detalhado texto contendo as alterações desenvolvidas por ele em sua montagem de 1969 no Schiller-Theater Werkstatt, bem como acrescentando diversas sugestões à encenação. Beckett ainda dirigiria a peça em mais duas ocasiões, na França com Pierre Chabert como Krapp, no Théâtre d'Orsay em abril de 1975, e mais uma vez em inglês com Rick Cluchey no papel de Krapp, apresentada em Berlim, no Akademie der Künste, em setembro de 1977. Mais uma vez, Beckett mantivera as alterações propostas por ele durante a montagem berlinense de 1969, adaptando cada uma das duas encenações aos atores que interpretavam Krapp, bem como ao contexto de cada produção, e também procurando incorporar ao texto da peça as mudanças desenvolvidas durante os ensaios que considerava pertinentes.

Ainda segundo James Knowlson, na introdução do volume sobre A última gravação de Krapp (KNowLSON, 1992), o objetivo das alterações 
propostas por Beckett logo na abertura de sua primeira encenação da peça seria de atingir uma maior simplicidade e clareza das linhas gerais e para evitar qualquer elemento que parecesse supérfluo. Outra intenção importante seria de estabelecer contrastes maiores entre um silêncio meditativo e imobilidade, e, por outro lado, atividade rápida e barulhenta. Beckett escreveu em seu caderno de direção que havia cortado "tudo o que interfere com a súbita mudança da imobilidade para o movimento ou que torna isso lento" (BECKETT apud KNowlson, 1992, p. XIV, tradução nossa).

James Knowlson faz um levantamento detalhado das alterações em relação ao espaço cênico, bem como dos objetos cenográficos e jogos de cena de Krapp, incluindo sua gag com a banana:

Como consequência, algumas ações de Krapp foram removidas do jogo cênico inicial no palco: não existia mais o trancar e destrancar das gavetas tanto no início ou antes da gravação ao vivo de Krapp; as duas gavetas trancadas na parte da frente da mesa foram substituídas por uma gaveta destrancada lateral, situada no lado da mesa e, mais convenientemente, à esquerda de Krapp; Krapp não remexe mais em seus bolsos em busca de um envelope no qual ele escrevera anotações para uso no momento da gravação; os sons do primeiro drink foram totalmente removidos, com Krapp fazendo ao invés disso três jornadas separadas antes do jogo com a banana em direção ao cubículo iluminado nos bastidores, que foi acrescentado ao set pela primeira vez na produção do Schiller e a partir do qual ele carrega o livro de registro, as caixas [de estanho ao invés de papel cartão] contendo as fitas gravadas e, finalmente, o gravador de rolo em si. Talvez a mais importante dessas mudanças tenha sido a introdução desse recesso nos bastidores, pois isso oferecia um grande número de benefícios práticos: uma resposta à questão de para onde Krapp teria ido em busca de seus livros e sua bebida - um covil dentro de um covil para um homem que deliberadamente separou-se dos outros - uma outra fonte de interesse visual e, porque ficava acesa durante toda a peça, um elemento de iluminação ecoando a zona de luz na mesa de Krapp e contrastando com o escuro que o cercava. (KNowLSon, 1992, pp. XIV-XV, tradução nossa)

Essa detalhada descrição das alterações sofridas pela peça nos mostra o nível de rebuscamento almejado por Beckett em suas encenações, procurando enfatizar sentidos e circunstâncias dramáticas que imaginava como potentes e definidoras do texto dramatúrgico, bem como minimizando e até mesmo eliminando tudo aquilo que seria excessivo ou que, 
segundo Beckett, afetaria o melhor desenvolvimento da ação dramática e seus desdobramentos.

Outro ponto importante que foi mantido na encenação berlinense, segundo James Knowlson, teria sido o jogo clownesco com a casca de banana, mas com pequenas modificações, como por exemplo, em vez de atirá-la no primeiro momento em direção à plateia, Krapp passaria a atirá-la em direção ao fundo do palco, que se mantém na escuridão. Isso, segundo o pesquisador, seria uma forma de manter a ação dramática da peça confinada a área de ação cênica, pois, para Beckett, uma peça extremamente contida dentro do espaço da caixa cênica não apresentaria condições coerentes para a ruptura da quarta parede no momento em que Krapp, no texto original, empurrava a casca de banana em direção à plateia. Também foram modificados detalhes do figurino, especialmente aqueles de aspecto mais clownesco, como as calças curtas demais para o personagem, os bolsos grandes e característicos de espetáculos circenses e de clowneria, e até mesmo a alusão sexual na cena em que a banana é colocada de volta em um dos bolsos do colete do personagem para em seguida ficar apenas com sua ponta para fora. No lugar dessa ação cênica, Beckett optou na encenação de Berlim por uma estratégia diversa, onde o restante da banana era atirado por Krapp em direção ao fundo do palco, para que ele pudesse, em seguida, correr em direção ao cubículo iluminado no fundo do palco em busca de seus apetrechos, para finalmente poder ouvir sua gravação.

Beckett demonstrou certo descontentamento com a excessiva clowneria original do texto de 1958, optando quando da montagem no Schiller-Theater Werkstatt por uma representação do personagem como um velho cansado, fraco e falho, em contraponto à imagem original clownesca do personagem. Portanto, fica claro que as mudanças proporcionadas pela direção se não buscavam tornar a representação naturalista, ao menos buscaram eliminar quaisquer elementos excessivamente exagerados que pudessem proporcionar uma leitura por parte do espectador no sentido de uma clowneria ou de um espetáculo com características próximas ao circo e ao music-hall e, mais precisamente, forneceram ao velho Krapp uma potência expressiva e uma limpeza em relação à sua linguagem cênica que ampliaram sua força dramática.

Outro ponto interessante das montagens de $A$ última gravação de Krapp por Beckett se refere às imagens em branco e preto. Conforme menciona James Knowlson:

Quando dirigiu Krapp's last tape, Beckett estava preocupado não apenas [...] em estabelecer uma complexa teia de imagens em branco e preto, 
mas também com a organização e o tempo das várias sequências de montagem. Ele trabalhou, por exemplo, com os vários atores que representaram Krapp sob sua direção em busca de distinguir claramente a voz mais jovem em relação à mais velha, e suas notas de direção são focadas em como o Krapp que vemos em cena reage de formas contrastantes a diferentes assuntos, climas e tons das gravações. Com $A$ última gravação de Krapp Beckett criou, portanto, uma aparentemente simples embora complexa peça que utiliza uma mistura de som e imagem e coloca em operação alguns dos princípios de montagem delineados por Arnheim [teórico do cinema cujos escritos foram estudados por Beckett em sua juventude]. Dirigindo a peça, ele deve ter sentido algumas vezes que não estava longe de realizar algumas de suas ambições de juventude, embora em um veículo diverso. (KNowlson, 2003, p. 120, tradução nossa)

Procuramos abordar, embora de forma rápida e superficial, a extensa e documentada relação de Samuel Beckett com a encenação de suas peças teatrais. Partindo dos elementos que o levaram a se tornar um encenador teatral, ou mais especificamente, um encenador-revisor de si mesmo, como define Stanley Gontarski (GONTARSKI, 2008), e passando pela reflexão acerca de depoimentos de encenadores, atores e estudiosos de sua obra teatral, este artigo busca esboçar, ainda que em linhas gerais e de forma sucinta, as principais características do Beckett diretor de teatro. Tendo como foco comentários e análises acerca de sua primeira encenação de $A$ última gravação de Krapp, procuramos desenvolver uma reflexão que também dialogasse com aspectos provenientes de outras encenações da mesma peça, bem como de outras obras teatrais de Beckett. Acreditamos que esse mergulho em uma obra tão fascinante e complexa, amplamente registrada e documentada por atores, diretores, especialistas e pelo próprio autor, tenha apenas se iniciado com este trabalho, que sem dúvida deixa aberta a possibilidade de realização de estudos posteriores mais aprofundados e extensos que abordem a relação entre o Beckett dramaturgo e o Beckett encenador. I 


\section{REFERÊNCIAS BIBLIOGRÁFICAS}

ADORNO, Theodor W. Notes on Beckett. In: Journal of Beckett Studies. 2010, Vol.19, n.2, pp. 157-178.

ANDRADE, Fábio de Souza. Samuel Beckett: o silêncio possível. São Paulo: Ateliê Editorial, 2001.

ASMUS, Walter D. Practical aspects of theatre, radio and television - rehearsal notes for the german premiere of Beckett's That Time and Footfalls at the Schiller-Theater Werkstatt, Berlin (directed by Beckett). In: Journal of Beckett Studies. Trad. Helen Watanabe. Summer 1977, n.2. pp. 82-95.

BECKETT, Samuel. The complete dramatic works. London: Faber and Faber, 1990. Esperando Godot. Trad. Flávio Rangel. São Paulo: Editora Abril, 1976. A última gravação de Krapp. Trad. Felipe de Souza. São Paulo: 1999. Passos. Trad. Felipe de Souza. São Paulo: 1998.

Fim de partida. Trad. e prefácio Fábio de Souza Andrade. São Paulo: Cosac Naify, 2002.

Esperando Godot. Trad. e prefácio Fábio de Souza Andrade. São Paulo: Cosac Naify, 2005.

. Dias felizes. Trad. e prefácio Jaime Salazar Sampaio. 3ạ ed. Lisboa: Editorial Estampa, 1998.

Dias felizes. Trad. e prefácio Fábio de Souza Andrade. São Paulo: Cosac Naify, 2010.

Teatro de Samuel Beckett. Lisboa: Arcádia, s/d.

BERRETINI, Celia. A linguagem de Beckett. São Paulo: Perspectiva, 1977.

BERRETINI, Celia. Samuel Beckett: escritor plural. São Paulo: Perspectiva, 2004.

BIRKENHAUER, Klaus. Beckett. Trad. Federico Latorre. Madrid: Alianza Editorial, 1976. 
CHABERT, Pierre (ed.). Revue d'Esthétique: Hors série 1990. Paris: Jean-Michel Place, 1990.

COHN, Ruby. Back to Beckett. Princeton: Princeton University Press, 1974. Just play: Beckett's theater. Princeton: Princeton University Press, 1980.

DELEUZE, Gilles. O esgotado. In: Sobre o teatro. Trad. Ovídio de Abreu e Roberto Machado. São Paulo: Zahar, 2010. pp. 65-111.

ESSLIN, Martin. Twentieth century interpretations of Samuel Beckett: a collection of critical essays. New Jersey: Prentice Hall, 1965.

O Teatro do absurdo. Trad. Barbara Heliodora. Rio de Janeiro: Zahar, 1968.

FARIAS JÚNIOR, Manoel Moacir Rocha. Beckett: silêncios. São Paulo: Annablume, 2011.

FLETCHER, John; SPURLING, John. Beckett: a study of his plays, London: Eyre Methuen, 1972.

GONTARSKI, S. E. The intent of undoing in Samuel Beckett's dramatic texts. Bloomington: Indiana University Press, 1985.

GONTARSKI, S. E (Org.). On Beckett: essays and criticism. New York: Grove Press, 1986.

GONTARSKI, S. E. The theatrical notebooks of Samuel Beckett Vol. 4: The shorter plays. London and New York: Faber and Faber and Grove Press, 1999.

GONTARSKI, S. E. Revisando a si mesmo: o espetáculo como texto no teatro de Samuel Beckett. In: Sala Preta - revista do PPG em Artes Cênicas ECA-USP. Trad. Robson Corrêa de Camargo e Adriana Fernandes. São Paulo: ECA-USP, 2008, n.8, pp. 261-280.

GUSSOV, Mel. Conversations with and about Beckett. New York: Grove Press, 1996. HARMON, Maurice (ed.). No author better served: the correspondence between Samuel Beckett and Alan Schneider. Cambridge: Harvard University Press, 1998. 
JANVIER, Ludovic. Beckett. Trad. Léo Schlafman. Rio de Janeiro: José Olympio Editora, 1988.

KALB, Jonathan. Beckett in performance. Cambridge: Cambridge University Press, 1991.

KNOWLSON, James. Krapp's Last Tape: the evolution of a play, 1958-1975. In: Journal of Beckett Studies. Winter 1976, n.1, s-p.

KNOWLSON, James. Practical aspects of theatre, radio and television extracts from an unscripted interwiew with Billie Whitelaw by James Knowlson. In: Journal of Beckett Studies. Summer 1978, n.3, pp. 85-90.

KNOWLSON, James; MCMILLAN, Dougald (eds.). The theatrical notebooks of Samuel Beckett vol.1: Waiting for Godot. New York: Grove Press, 1994.

KNOWLSON, James (ed.). The theatrical notebooks of Samuel Beckett vol.3: Krapp's Last Tape. London: Faber and Faber, 1992.

KNOWLSON, James; KNOWLSON, Elizabeth (eds.). Beckett remembering, remembering Beckett. London: Bloomsbury, 2007.

LAWLEY, Paul. Stages of identity: from Krapp's last tape to Play. In: PILLING, John (ed.). The Cambridge Companion to Beckett. Cambridge: Cambridge University Press, 1994.

LEHMANN, Hans-Thies. Teatro pós-dramático. Trad. Pedro Sussekind. $2^{\mathrm{a}}$ ed. São Paulo: Cosac Naify, 2011.

MCMILLAN, Dougald; FEHSENFELD, Martha. Beckett in the theatre: the author as a practical playwright and director. London: John Calder, 1988.

MCMULLAN, Anna. Beckett as director: the art of mastering failure. In: PILLING, John (ed.). The Cambridge Companion to Beckett. Cambridge: Cambridge University Press, 1994.

OPPENHEIM, Lois. Directing Beckett. Ann Arbor: The University of Michigan Press, 1997.

PAVIS, Patrice. Diccionario del teatro. Trad. Fernando de Toro. Barcelona: Paidós, 1983. 
POUNTNEY, Rosemary. Theatre of shadows: Samuel Beckett's drama 1956-1976. Gerrards Cross: Colin Smythe, 1988.

RAMOS, Luiz Fernando. O parto de Godot e outras encenações imaginárias. São Paulo: HUCITEC, 1999

ROBINSON, Michael. The long sonata of the dead: a study of Samuel Beckett. London: Rupter Hart-Davis, 1970.

VASCONCELLOS, Cláudia Maria de. Teatro inferno: Samuel Beckett. São Paulo: Terracota, 2012. 